\title{
Brand Culture Communication under New Media Age
}

\author{
Xiaoqing Qin
}

Shandong Yingcai University, Ji'nan, 250003, China

\author{
Keywords: New media age, Brand culture, Communication
}

\begin{abstract}
Among three drivers, consumption plays a more and more important role in pulling increase of national economy. From the perspective of proportion of products in the consumer market, brand culture is also highlighted day by day. At present, online consumption is a new path, and it has great development potential in the future. At the same time, continuous variation in media environment also makes operators begin to realize the fact that traditional brand communication mode already cannot adapt to constantly changing network environment. Under the current new network environment, therefore, new approach of brand culture communication is of great importance. On this basis, this paper mainly discusses communication of brand culture communication under new media age.
\end{abstract}

\section{Introduction}

With the coming of consumption age, brand becomes an important factor of enterprise competition. Variation in media environment urges brand operators to face constantly changing communication environment and consumers. While old brand communication patterns under great challenges, it is of great importance for how to explore for a brand culture communication pattern conforming to era characteristics under new digital age. Now, enterprise development attaches more importance to market grasp. For enterprise development, the person who possesses the market will possess the future. In the current enterprise development, however, brand culture has undoubtedly become the core of an enterprise. It is the foundation for long-term development of the enterprise. Therefore, to lay emphasis on brand culture communication is of great significance for enterprise survival and development. With the coming of new media age, brand culture presents new characteristics. At the same time, brand communication is also faced with new challenges. Therefore, it is necessary for the enterprises to seek for more effective brand culture communication paths and thus realize enterprise brand strategies.

\section{Summary of Brand Culture under New Media Age}

\section{Definition of brand culture}

Brand culture is collection of all culture in a company. These factors include advertisement, product, enterprise, consumer, competitor and others alike. To obtain long-term development in the current market, an enterprise must have its own core enterprise culture. Besides, it is also necessary for the enterprise to continuously research its brand culture and find out integrating points between the culture in this brand and the current market, so as to really step into the heart of consumers and achieve the purpose of enterprise marketing.

\section{Characteristics of brand culture under new media age}

Give play to the guiding role of the market

The current consumer market belongs to a consumer market under new media age. Therefore, enterprises should make decisions by combining the market orientation under new media age while building product brands. Product brand building is a thing completely different from product manufacturing. Product is only simple production; while brand building requires a series of procedures. Enterprises may make enterprise brand culture prior to or in the course of product 
production. However, brand culture at this time is not simply a kind of cultural frame. However, specific brand culture contents need to be determined according to actual conditions. In the process of brand determination, it should be made clear that brand culture is completely different from statement of brand name. Brand culture is a kind of expression of product internal culture; while the name of product brand culture is only used to identify this product. From the perspective of brand value, brand value is from consumers' affirmation at most cases, especially in the consumer market under new media age. Recognition of online consumers for brand is just the meaning of true brand value. For the present new media age, network market is the foundation for enterprise survival and development. Enterprise brand is only one of network needs of new media age. Brand exists due to the need of market. Radically, product brand is connotation given by the market. It may become brand culture only after being accepted by market value.

Give play to the action of cultural representation

Radically, product brand is a kind of cultural representation pattern. Brand marketing is an external carrier of cultural communication. Each enterprise has its own brand. More importantly, each enterprise needs to add brand elements to this brand, giving more cultural characteristics to it. However, such elements include product color, identification, packaging, brand name, ad, logo and others. Enterprises use these elements to construct their brand cultures, and transfer product information to consumers. The greatest function of these elements is to enable consumers to quickly position product brands in numerous similar products through these product elements, so as to guide the consumers to buy these products, especially under promotion of the new pattern - online shopping in new media age. Shopping is completed by virtue of network virtualization. Under the circumstance of catching no sight of real objects by consumers, it is of particular importance for product elements. Consumers can only position product brands through these elements, so as to drive network consumption. A famous American economist used to describe brand culture as follows: "actually, it is made cultural". This sentence points out that the formation process of a brand is just the formation process of a kind of enterprise culture. Moreover, both items finally are united in enterprise products. In the real market, it needs diversity to create conditions for diversified brand cultures.

Give play to the action of public communication

It is necessary for enterprise marketing to create new patterns under new media age, so as to give solutions to enterprise marketing. In the process of brand communication, enterprises achieve the function of promotion. Wider communication will have higher influence on consumers. Such public communication feature of brand allows brand culture to be communicated in a better way, especially under the current new media age. It will have better communication effects by virtue of network characteristics.

\section{Challenges Facing Brand Communication under New Media Age}

\section{Influence of multimedia information development on advertising communication}

In the contemporary era, China is in rapid developmental stage of information. In particular, development of communication technology also results in radical reform to modern transmission mode. Firstly, media are diversified. On the basis of traditional media, some new media appear one after another. Some new media radically changed information communication modes, including satellite communication and internet technology. At the same time, these new technologies also quickened information spreading speed. The feature of globalization becomes more obvious. Secondly, it resulted in information inundation phenomenon and information explosion phenomenon. The mankind has already stepped into information society. Countless kinds of information make people unable to distinguish right from wrong. More seriously, such information also makes people unable to accept. Under such information environment, promotion efficiency of advertising trends to decrease. While selecting new media, advertisers also don't know how to make a choice. In single medium age, information advertised for more than three times would influence consumers. Nowadays, however, information even advertised for one hundred times may still have no influence 
on consumers. While advertising propagation speed keeps quickly decreasing, the frequency of enterprise product promotion trends to increase, resulting in great increase in enterprise marketing costs.

\section{Reduced transmission efficiency of mass media}

To some extent, traditional media will be impacted by modern media. Its transmission efficiency will be gradually reduced. Press and television have already lost previous effects. Consumers will be influenced by media. To guarantee effectiveness and authenticity of advertising, enterprises can directly face target groups, and effectively become advertise transmission tools according to rapid development of media, for instance, elevator advertising, public traffic system advertising, and building advertising. The places that people have contact with can become effective carriers of advertising. We can put it in this way: mass decentralization media further become the first choice of enterprise media by virtue of low cost and definite audiences. Moreover, rapid development of mass decentralization media also has great influence on traditional media and modern media. At the same time, mass decentralization media can attract more audiences.

\section{Reduced brand loyalty}

With rapid development of China's economy, people also quicken their life steps accordingly. Fast pace of life has great influence on people's life style and value judgment. New information continuously came forth. While continuously accepting information, people also learnt how to distinguish information. However, fast pace of life led people to have no enough time and energy to deal with various kinds of information. People will only choose information in a small scope or information that they think useful. Actually, they only know how to use such information in a simple way. While making procurement decisions, their correct consciousness will tell them to choose useful products. For pattern of manifestation of such quick culture, people are not crazy about a certain brand. On the contrary, they need to continuously exchange brand information and explore for various challenges of new things and objects. This kind of information communication and reception requires the manufacturers to keep consistent orientation after product service and during information communication.

\section{Brand Culture Communication Routes under New Media Age}

\section{Complete rules and regulations}

Under new media age, rules and regulations are used as various codes of employee conduct, stimulation and restriction clauses and service product quality. Such rules and regulations further indicate, in a written form, what employee conducts are led by socialist core values and what sense of value is unconformable to moral quality. Just because of various rules and regulations, core value of brand can be converted from the consciousness level to the behavior level. Instead of talk in generalities, it includes a series of words that can be said and operated. We all know that brand value of McDonald's is "value, cleanness, service and quality", namely high food quality and considerate service. Moreover, it means to formulate McDonald's business training manual, management development training manual, quality guidance manual and other manuals, so as to further standardize and guide work conducts of its employees. These rules and regulations will make standards and detailed work flows for McDonald's food processing and shop cleanness. For instance, it is definitely stated in its quality guidance manual: in the process of hamburger frying, the cook should turn over along the hamburger, and cannot throw hamburger like bricks. Moreover, fried chips that don't be sold out after 7 minutes of frying should be abandoned.

\section{Emphasize presentation of brand core value in advertising}

Under influence of new media environment, promotion mode of product information is different from that of advertise brand culture. In advertising and promotion process of brand culture, the 
advertising contents contact more with commitment of brand products on consumer benefits, such as sense of status, sense of safety and sense of fashion. Advertising contents refer to products emotionally accepted by target consumers. The ultimate objective is to generate resonation among consumer groups for the core value system. To present its core value, we can use a simple slogan. On television or newspaper, we often see slogans exclusively belonging to some brands, for instance, people-oriented science and technology of Nokia. At the same time, it can also effectively combine words with pictures. Many enterprises created slogan belonging to this brand while forging a brand. The slogan should give expression to features of this product, making people to have impulsion to buy this brand while seeing this advertising.

\section{Enhance combination in various strategic stages of news propaganda and brand culture}

We cannot acquire background information of some products simply from sponsor activities or advertising, such as research and development technology, human resource and cultural background. In the process of news propaganda, we can properly make up these deficiencies, making brand image to be not that thin. Sensational effect of news will make people willing to actively acquire the contents of news, having better effects than advertising from various aspects. However, we should emphasize combination of various core targets in brand culture strategy in the process of news propaganda due to timeliness of news, so as to achieve the ultimate objective. In the process of its brand culture promotion, Haier made the most of news propaganda to obtain relatively substantial economic benefits.

\section{Emphasize processing of information feedback in the process of brand culture communication}

Brand culture communication is not simple cultural transmission. Brand culture is a kind of cultural phenomenon. At the same time, it also has various features of "cultural stream". In other words, it is impossible for brand culture enterprises or brand culture to rest on one level for ever. On the contrary, they will change with time accordingly. With continuous communication and development of brand culture, consumers' cultural value will be further feed back to enterprises, and provide new cultural features and new cultural patterns to the enterprises. In the process of enterprise development, the enterprises should capture such information, and make further adjustment to such feedback information used as fundamental brand culture. Any conversion of consumers' cultural values or blind adjustment to brand culture may have huge influence on enterprise business activities, or even lead to bankruptcy.

\section{Conclusion}

Nowadays, there are numerous technical means for media communication under new media age. Traditional thought of band culture communication cannot meet needs of enterprise development. Good brand culture communication routes can allows the enterprises to set up brand images in a quicker way. However, exploration for such communication routes requires the enterprises to have a complete understanding of features of brand culture and dilemma of brand culture communication under new media age. Therefore, the enterprises must innovate and develop brand culture communication routes, so as to occupy a certain plate or even stand out in increasingly fierce market competition.

\section{Acknowledgments}

Name of this subject: Research on Professional Moral Quality Cultivation Mode of Business College Students based on School-enterprise Cooperation (No.: SKKT-12064) 


\section{References}

[1] Zhou Chaoqi, Hou Longwen and others, Brand Culture: Cultural Connotation, Philosophical Concept and Representation, Beijing: Commodity of Economic Management Publishing House, 2012: 24-25;

[2] Zhou Hui and Peng Xingjian, Management Logics of Enterprise Life Model, Nankai Business Review, 2012, (03): 57-58;

[3] Zhou Yang, Analysis on Internet Marketing under New Media Age, Economic Vision, 2011, (12): 134-135;

[4] Xu Xiaoyong, Lv Jianhong and Chen Yiwen, Research on Customer Praxiology of Brand Image, Advances in Psychological Science, 2013, (11): 151-152;

[5] Guan Jingyu, Achievement Leading Pattern and Question Leading Pattern - Research on Environment News Media of People's Daily and Southern Weekend under Frame Theory, Lanzhou University, 2014: 167-169;

[6] Wang Jingjing, From Advertising to Terminal - Analysis on New Tendency of Brand Building, Modern Economics, 2008 (12): 178-179. 